\title{
Manufacturer-Retailer Channel Interactions and Implications for Channel Power: An Empirical Investigation of Pricing in a Local Market
}

\author{
Vrinda Kadiyali • Pradeep Chintagunta • Naufel Vilcassim \\ Johnson Graduate School of Management, Cornell University, Ithaca, New York 14853, kadiyali@cornell.edu \\ Graduate School of Business, University of Chicago, Illinois 60637, pradeep.chintagunta@gsb.uchicago.edu \\ Marshall School of Business, University of Southern California, Los Angeles, California 90098, vilcass@almaak.usc.edu
}

\begin{abstract}
The issue of "power" in the marketing channels for consumer products has received considerable attention in both academic and practitioner journals as well as in the popular press. Our objective in this paper is to provide an empirical method to measure the power of channel members and to understand the reasons (demand factors, cost factors, nature of channel interactions) for this power. We confine our analysis to pricing power in channels. We use methods from the game-theory literature in marketing on channel interactions to obtain the theoretical framework for our empirical model. This literature provides us a definition of power-one that is based on the proportion (or percentage) of channel profits that accrue to each of the channel members.

There can be a variety of possible channel interactions between manufacturers and retailers in channels. The theoretical literature has examined some of these games. For example, Choi (1991) examines how channel profits for manufacturers and retailer vary if channel interactions are either vertical Nash, or if they are Stackelberg leaderfollower with either the manufacturer or the retailer being the price leader. Each of these three channel interaction games has different implications for profits made by manufacturers and retailers, and consequently for the relative power of the channel members.

In contrast to the previous literature that has focused largely on the above three channel interaction games, our model extends the game-theoretic literature by allowing for a continuum of possible channel interactions between manufacturers and a retailer. Furthermore, for a given product market, we empirically estimate from the data where the channel interactions lie in this continuum. More critically, we obtain measures of how channel profits are divided between manufacturers and the retailer in the product market, where a higher share of channel profit is associated with higher channel power. We then examine how channel power is related to demand conditions facing various brands and cost parameters of various manufacturers.
\end{abstract}

In going from game-theory-based theoretical models of channel interactions to empirical estimation, we use the "new empirical industrial organization" framework (Bresnahan 1988). As part of this structural modeling framework, we build retail-level demand functions for the various brands (manufacturer and private label) in a given product category. Given these demand functions, we obtain optimal pricing rules for manufacturers and the retailer. In determining their optimal prices, manufacturers and the retailer account for how all the players in the channel choose their optimal prices. That is, we account for dependencies in decision making across channel members. These dependencies are characterized by a set of "conduct parameters," which are estimated from market data. The conduct parameters enable us to identify the nature of channel interactions between manufacturers and the retailer (along the continuum mentioned previously). In addition to the demand and conduct parameters, manufacturers' marginal costs are also estimated in the model. These marginal cost estimates, along with the manufacturer prices and retail prices available in our dataset, enable us to compute the division of channel profits among the channel members. Hence, we are able to obtain insights into who has pricing power in the channel.

In the empirical application of the model, we analyze a local market for two product categories: refrigerated juice and tuna. In both categories, there are three major brands. The difference between them is that the private label has an insignificant market share in the tuna category. Our main empirical results show that the usual games examined in the marketing literature do not hold for the given data. We also find that the retailer's market power is very significant in both these product categories, and that the estimated demand and cost parameters are consistent with the estimated pattern of conduct between the manufacturers and the retailer. Given the evidence from the trade press of intense manufacturer competition in these categories, as well as the "commodity" nature of these products, the result of retailer power appears intuitive.

(Channel Power; Private Labels; Competitive Games) 


\section{Introduction}

The issue of "power" in the marketing channels for consumer products has received considerable attention in both academic and practitioner journals as well as in the popular press (e.g., Messinger and Narasimhan 1995, Johnson 1988, Business Week 1992). The conventional wisdom is that power rests with the retailer and has increasingly shifted from the manufacturer to the retailer over time.

Several reasons have been cited for retailer power. Some writers (e.g., Jones 1990) believe that "intense competition" among manufacturers is responsible for this. The introduction of private label brands is another important consideration in determining the nature of manufacturer-retailer interaction (see Raju et al. 1995, Hoch and Banerjee 1993, Hoch 1996). As Salmon and Cmar (1987) note, the high quality of private labels in some categories gives the retailer leverage when dealing with the national brand manufacturers. Other reasons for retailer power include increased concentration at the retail level, the scarcity of shelf space accompanied by a large increase in the number of new product introductions, and the use of advanced information technology. The increase in trade promotions at the expense of consumer advertising, the emergence of the practice of slotting fees, and in some extreme cases the practice of offering the retailer "guaranteed profit margins" (Krishnan and Soni 1997) are seen as manifestations of retailer power.

Empirical research in this area has provided an interestingly opposing view to the popular view of channel power. By examining a variety of industries, Messinger and Narasimhan (1995) report that there is no evidence of retailer profitability being better than manufacturer profitability over the period 1961-1991. Farris and Ailawadi (1992) report similar findings based on an analysis of data from the Compustat database for the period 1971-1990. Our objective in this paper is to provide another empirical method to measure the power of channel members and to understand the reasons (demand factors, cost factors, nature of channel interactions) for this power. We confine our analysis to pricing power in channels because of lack of data on other dimensions of competition. Furthermore, unlike some previous studies, our focus is not on the shift, if any, in channel power, but on its measurement over the period of analysis.

Contrasting our approach to the studies cited previously, the empirical analysis in this paper is based on an industry case study rather than a crossindustries analysis. We use methods from the gametheory literature in marketing on channel interactions to obtain the theoretical framework for our empirical model. This literature provides us a definition of power-one that is based on the proportion (or percentage) of channel profits that accrue to each of the channel members.

Consider, for example, the model of manufacturerretailer interaction in Choi (1991). He examines how channel profits for manufacturers and retailer vary if channel interactions are either vertical Nash, or if they are Stackelberg leader-follower with either the manufacturer or the retailer being the price leader. Each of these three channel interaction games has different implications for profits made by manufacturers and retailers, and consequently for the relative power of the channel members.

In contrast to the previous literature that has focused largely on the above three channel interaction games, our model extends the game-theoretic literature by allowing for a continuum of possible channel interactions between manufacturers and a retailer. Furthermore, for a given product market, we empirically estimate from the data where the channel interactions lie in this continuum. More critically, we obtain measures of how channel profits are divided between manufacturers and the retailer in the product market, where a higher share of channel profit is associated with higher channel power. We then examine how channel power is related to demand conditions facing various brands and cost parameters of various manufacturers.

In going from game-theory-based theoretical models of channel interactions to empirical estimation, we use the "new empirical industrial organization" framework (Bresnahan 1987). As part of this structural modeling framework, we build retail-level demand functions for the various brands (manufacturer and private label) in a given product category. Given these demand functions, we obtain optimal pricing rules for manufacturers and the retailer. In determining their 
optimal prices, manufacturers and the retailer account for how all the players in the channel choose their optimal prices. That is, we account for dependencies in decision making across channel members. These dependencies are characterized by a set of "conduct parameters," which are estimated from market data. The conduct parameters enable us to identify the nature of channel interactions between manufacturers and the retailer (along the continuum mentioned previously). In addition to the demand and conduct parameters, manufacturers' marginal costs are also estimated in the model. These marginal cost estimates, along with the manufacturer prices and retail prices available in our dataset, enable us to compute the division of channel profits among the channel members. Hence, we are able to obtain insights into who has pricing power in the channel.

The use of the NEIO methodology to study marketing channel issues can be contrasted to most empirical studies in the channels literature that have used the structure-conduct-performance paradigm to measure market power (Messinger and Narasimhan 1995, Farris and Ailawadi 1992, Connor and Peterson 1992). These studies estimate reduced-form relationships between the structure of industries (e.g., manufacturer and retailer concentration ratios, new product introductions, adoption of scanners, etc.) and performance (e.g., accounting profits). However, empirical industrial organization researchers have demonstrated that conduct and performance are endogenously determined because of feedback from one to the other. Ignoring the endogeneity of conduct leads to biased estimates of both conduct and performance measures (see Bresnahan 1989). Hence, the issues of endogeneity and simultaneity must both be addressed, and the NEIO framework enables us to do that.

In the empirical application of the model, we analyze a local market for two product categories: refrigerated juice and tuna. In both categories, there are three major brands. The difference between them is that the private label has an insignificant market share in the tuna category. Our main empirical results show that the usual games examined in the marketing literature do not hold for the given data. We also find that the retailer's market power is very significant in both these product categories, and that the estimated demand and cost parameters are consistent with the estimated pattern of conduct between the manufacturers and the retailer. Given the evidence from the trade press of intense manufacturer competition in these categories, as well as the "commodity" nature of these products, the result of retailer power appears intuitive.

The rest of this paper is organized as follows. In the next section, we discuss the model to estimate channel power in this industry. In $\S 3$ we discuss the data used to estimate the model, as well as some estimation details; $\S 4$ has the results of the study, and $\$ 5$ concludes.

\section{Model Formulation}

Marketing researchers have built several models of channel interactions based on microeconomic theory. Examples include Jeuland and Shugan (1983), McGuire and Staelin (1983), Coughlan (1985), Coughlan and Wernerfelt (1989), Choi (1991), and Lee and Staelin (1997). The question we ask is: Can we use these models to measure channel power? If not, what modifications need to be made to these models so as to make them more amenable to the empirical measurement of channel power? In this section, we first consider representative theoretical models from Choi (1991). We then lay out our estimating model and contrast it to some theoretical representations of channel power.

\subsection{Theoretical Models of Channel Conduct: Are They Appropriate for Empirical Applications?}

There have been four models of channel interactions considered in the literature, each with different numbers of channel members: (1) A single manufacturer and a single retailer channel (e.g., Jeuland and Shugan 1983); (2) a single manufacturer being paired with a single retailer, but there are two (or more) such exclusive pairs (e.g., McGuire and Staelin 1983); (3) two manufacturers interact with a common retailer (Choi 1991); (4) two manufacturers interact with two retailers, and the relationships are not exclusive (Lee and Staelin (1997). As we do not have data on retail competition to empirically test the Lee and Staelin model, we focus on the Choi model of (3). In the diagram below, we label the various channel interactions considered in the Choi model. 
The numbers in the above diagram represent the various channel interactions. Choi makes the following assumptions about these interactions.

Assumption 1. Interaction along arrow 1; i.e., competition between manufacturers is Bertrand-Nash

Assumption 2. Interaction along 2 has to the same as interaction along 3.

Assumption 3. Interaction along 2 and 3, i.e., between each manufacturers and the retailer, is one of three possible configurations: vertical Nash; manufacturer as Stackelberg leader; or retailer as Stackelberg leader. Therefore, Choi allows for three types of pricing games or vertical arrangements in price setting (similar assumptions are made in the Lee-Staelin model).

Choi then analyzes the profits made by manufacturers and the retailer in each of the three game scenarios. In this manner, he connects the channel interaction (or the channel game) to channel power (or share of channel profits). By doing so, he provides insights into the nature of channel power. If we were to take the Choi model above to data to estimate channel power, the question we would ask is the following: Which of the three vertical arrangements or pricing games actually holds in a given market? Therefore, we are looking to estimate demand functions and the associated optimal manufacturer and retailer pricing rules for each of the games outlined above and determining which one best describes the data for the given product market.

Next, we go from seeing which of the three games best describes channel pricing in our product market to seeing how channel profits are split between each manufacturer and the retailer. For this, we would need manufacturers' marginal costs, manufacturers' selling prices (i.e., retailers' marginal costs) and retailer's selling prices. The difference between the first two would yield manufacturer margins, and the difference between the latter two the retailer margins. Our data include both manufacturers' and the retailer's selling prices. Therefore, if we can estimate manufacturers' marginal costs from the data (we show later how this is estimated directly from the first-order pricing conditions for the manufacturer), both manufacturer and retailer margins for each time period can be computed. Using these computed margins and weighting them by weekly sales, we can get the average (over all time periods) quantity-weighted margin. By comparing them we can estimate how channel profits are split. Therefore, using the Choi model we can determine which of the three games describes the market interactions, as well as the manner in which channel profits are split. From these estimates of channel profit division, we can determine who has power in the channel, by defining power as the ability to obtain a larger share of channel profits.

Three issues arise in the application of the Choi model to data from any product market. First, the model assumes that manufacturers (M1 and M2 above) react in a Bertrand-Nash manner with each other (along arrow 1 above). However, in almost every empirical study of manufacturer-manufacturer competitive interactions, this assumption has been found to be inconsistent with the data (see Bresnahan 1989). Therefore, a more general model of M1-M2 interactions is needed. Several pricing games are possible in this interaction. For example, M1 may be a Stackelberg leader or follower to M2, or M1 and M2 may be tacitly colluding in setting manufacturer prices to R1. In principle, an empirical investigation of channel power needs to allow for each of these alternative scenarios of interaction among manufacturers.

The second issue that arises in implementing the model described above is whether we assume that the game across manufacturer-retailer pairs is the same (i.e., whether the interaction between $\mathrm{M} 1$ and $\mathrm{R} 1$ is the same as that between M2 and R1). Depending on the product market, different manufacturers will have different channel power and pricing strategies with the retailer. For example, it is possible that a manufacturer with a larger market share is a Stackelberg leader in setting manufacturer price to retailer, but a smaller manufacturer is a Stackelberg follower. Hence, it is important to allow for such heterogeneity in manufacturer-retailer interactions.

The third issue with using the above model for estimating pricing power in channels is whether the "menu" of three possible interactions (vertical Nash; manufacturer as Stackelberg leader; and retailer as Stackelberg leader) adequately captures the range of possible interactions among the channel members. Folk theorems tell us that the list of games considered 
above, i.e., Bertrand-Nash, manufacturer Stackelberg leader, and retailer Stackelberg leader are just three of possibly infinite pricing games or vertical arrangements. To really understand what pricing game or arrangement for splitting channel profit holds in the data, the above menu needs to be expanded to allow for other kinds of possible interactions (e.g., accommodating behavior). In other words, a more comprehensive menu needs to be considered.

Addressing all the above issues in the context of a tractable empirical model is a nontrivial task. Closedform solutions may not be available for all different scenarios of competitive channel interactions. Stated differently, even if we developed a comprehensive menu as noted above, it may not be possible to obtain the corresponding empirical model. In the next section we attempt to provide one possible approach to obtaining a tractable empirical model that is sufficiently comprehensive to accommodate several possible types of channel interactions.

\subsection{A General Estimable Model of Channel Power}

To account for the three issues raised above, we revisit Figure 1. As in the Choi model, we have 2 firms and 1 retailer, and a pool of consumers. However, we allow for a variety of possible price setting games (or vertical arrangements) and hence, a variety of channel profit splitting arrangements.

As mentioned before, we have data on only one retail chain (say, R1) for several manufacturers within a

Figure 1 Diagram of Channel Interactions from Choi (1991)

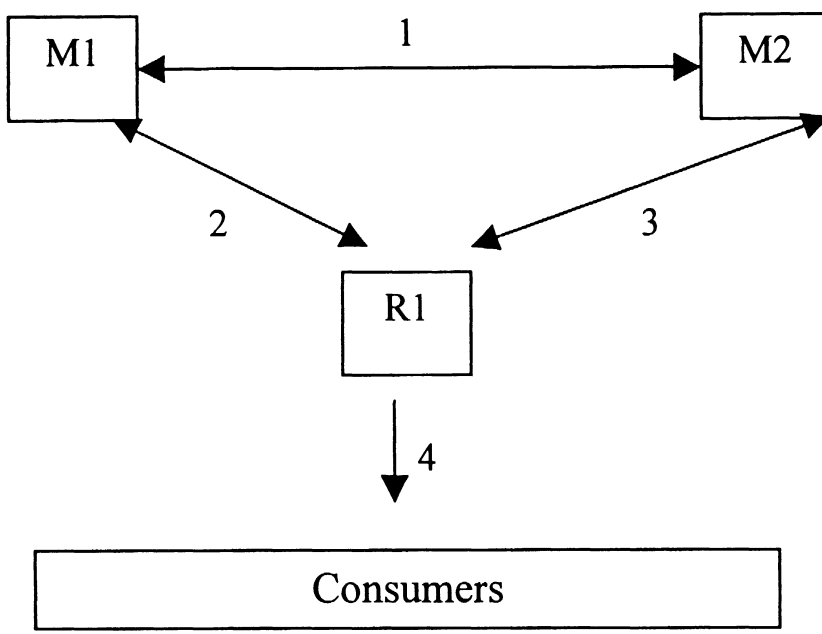

product category. Therefore, we are able to directly estimate only the interactions and power along arrows 2 and 3, i.e., between manufacturers and retailers. For the interaction between the two manufacturers (along arrow 1), our objective is to not impose any particular type (e.g., Bertand-Nash), for the reasons cited previously. Therefore, we allow for some general form of interaction between each pair of manufacturers. However, as we show later, we are unable to characterize the exact form of this general interaction. We estimate the parameters of the demand function (along 4) under the assumption that consumers are nonstrategic. Additionally, we focus our analysis on the interactions of two national brand manufacturers and the retailer in refrigerated juice categories, and three national brand manufacturers and the retailer in the tuna category. We also include the retailer's private label in refrigerated juice.

In formalizing the model of channel interaction, we first postulate retail-level demands for each brand (note that that this corresponds to interaction 4 in Figure 1). From there, we determine the retailer's category profit maximization rules and the own-brand profit maximization rule for each firm. We then show how to compute the split in the channel profits between each manufacturer and the retailer.

2.2.1. Demand Specification. We specify the demand facing a particular retail chain for each brand $(q)$ sold by this retailer. The demand is a singlelogarithmic function of four types of variables:

(1) The private label and national brand retail prices $(p)$ at this retailer's store.

(2) A demand shifter (ddshifter), or a variable that

Figure 2 An Extension of the Channel Interaction Diagram in Figure

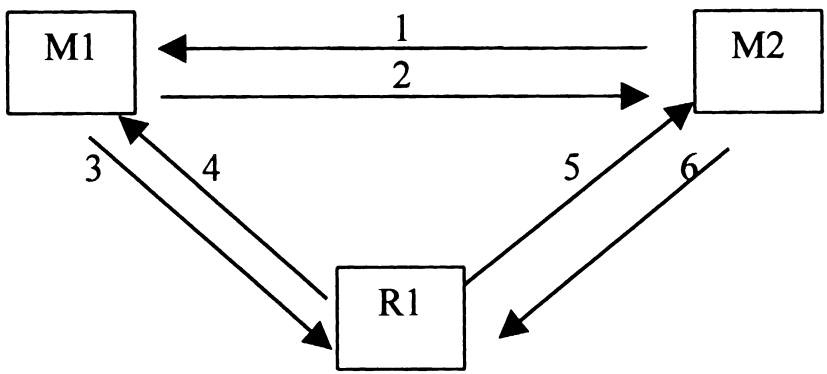


moves the demand functions. This variable is not controlled by the retailer or the manufacturer and is therefore treated as an exogenous variable.

(3) A deal variable for the brand (deal).

The rest of the discussion is for a category with three brands (refrigerated juice and tuna), but the analysis is easily extendable to categories with more brands.

For each brand $i, i=1,2$, and 3 we have

$$
\begin{aligned}
q_{i}= & a_{i}+b_{i}^{*} \ln \left(p_{1}\right)+c_{i}^{*} \ln \left(p_{2}\right)+d_{i} * \ln \left(p_{3}\right) \\
& +g_{i} * \text { ddshifter }+h_{i}{ }^{*} \text { deal }_{i} .
\end{aligned}
$$

We tried various specifications for the demand function including linear, log-log and semi-log. We found that the different models were quite comparable in terms of their fit to the data. The main advantage of the above specification is that it helps us to identify the conduct parameters (described later in the section) that are central to our understanding of channel interactions. Specifically, the price variables have to be in logarithmic form to obtain identification of the key competitive conduct parameters. Parker and Roller (1997) use a similar specification for the same reason. An additional advantage of the chosen specification is that it allows for nonlinearity in the relationship between prices and sales levels.

We also tried two variables for the demand shifters. The first one is a set of seasonal dummies. The second demand shifter is a measure of sales in this category in this geographic area other than in this chain. To the extent that there is direct retail level competition at the brand level, we would expect this variable to have a significant effect on sales for each brand under consideration. One important issue with the inclusion of such a variable is that it could be endogenous, and we address this issue in the estimation. As for the deal variable, it can enter either linearly or logarithmically. We found the linear form to perform better than the logarithmic form, and hence we chose the linear specification. Note that the demand function includes only the own deal variable rather than the deal variables for all brands because cross-deal effects were found to not have a significant impact. We also do not model the advertising decisions of firms because of lack of data.
2.2.2. Manufacturer and Retailer Pricing Decisions. Given the demand functions previously specified, each manufacturer $i$ is assumed to maximize its variable profit function given by

$$
\pi_{i}=\left(m p_{i}-m c_{i}\right)^{*} q_{i}
$$

where $\pi=$ profit, $m p=$ manufacturer price, $m c=$ marginal cost, and $q=$ the demand or sales as specified above. Each manufacturer is modeled as picking the profit-maximizing price of its brand. Note that the demand equation includes a deal variable, which is jointly determined by both the firm and the retailer. We do not model the optimization rule for this deal variable because of the lack of data on costs of deals and also to keep the estimated model tractable.

Consider the problem above for manufacturer 1, when it sets its optimal manufacturer price:

$$
\begin{gathered}
\pi_{1}=\left(m p_{1}-m c_{1}\right) *\left(a_{1}+b_{1} * \ln \left(p_{1}\right)+c_{1}^{*} \ln \left(p_{2}\right)\right. \\
\left.+d_{1} * \ln \left(p_{3}\right)+g_{1} * \text { ddshifter }+h_{1} * \operatorname{deal}_{1}\right) .
\end{gathered}
$$

Manufacturer 1 is choosing its optimal manufacturer price, keeping in mind how it expects other firms in the marketplace to react if it changes its price, including the retailer to whom the firm is selling. ${ }^{1}$ Consider first the vertical Nash situation as in Choi (which also assumes that manufacturer-to-manufacturer interactions are Nash). The first-order condition for the firm's profit maximization is then given by

$$
\begin{aligned}
& \left(m p_{1}-m c_{1}\right) *\left(b_{1} * \partial p_{1} / \partial m p_{1} * 1 / p_{1}+c_{1} * \partial p_{2} / \partial m p_{1}\right. \\
& \left.* 1 / p_{2}+d_{1} * \partial p_{3} / \partial m p_{1} * 1 / p_{3}\right)+q_{1}=0 .
\end{aligned}
$$

As $p_{1}=m p_{1}+r_{1}$, where $r_{1}$ denotes the retailer's markup on brand 1 , we have $\partial p_{1} / \partial m p_{1}=1+\partial r_{1} / \partial m p_{1}$. Recognizing that $p_{2}=m p_{2}+r_{2}$ where $r_{2}$ is retailer's markup on brand 2 , we have $\partial p_{2} / \partial m p_{1}=\partial m p_{2} / \partial m p_{1}$ $+\partial r_{2} / \partial m p_{1}$. Using the traditional NEIO literature terminology, the retailer's and other manufacturers' conduct can be represented by the vector $\left\{1+\theta\left(r_{1}, m p_{1}\right)\right.$, $\left.\theta\left(p_{2}, m p_{1}\right), \theta\left(p_{3}, m p_{1}\right)\right\}$. Hence, the first-order condition in Equation (4) can be rewritten as

\footnotetext{
${ }^{1}$ Therefore, we do not model the manufacturer-retailer interactions in terms of a bargaining model, as is often done in game-theoretic models of vertical relations.
} 


$$
\begin{aligned}
& \left(m p_{1}-m c_{1}\right) *\left(b_{1} *\left(1+\theta\left(r_{1}, m p_{1}\right)\right)\right. \\
& \quad * 1 / p_{1}+c_{1} * \theta\left(p_{2}, m p_{1}\right) * 1 / p_{2} \\
& \left.+d_{1} * \theta\left(p_{3}, m p_{1}\right) * 1 / p_{3}\right)+q_{1}=0 .
\end{aligned}
$$

In the Choi vertical Nash case, the manufacturer-tomanufacturer interactions are assumed to be (horizontal) Nash, i.e., $\partial m p_{2} / \partial m p_{1}=0$. Furthermore, $\partial r_{2} / \partial m p_{1}$ $=0$ for the vertical Nash case. Therefore, we have $\partial p_{2} /$ $\partial m p_{1}=\partial m p_{2} / \partial m p_{1}+\partial r_{2} / \partial m p_{1}=0+0=0$ in this case. Similar arguments hold for brands 3 and 4 . Therefore, Equation (4) can be rewritten as

$$
\begin{aligned}
& \left(m p_{1}-m c_{1}\right) *\left(b_{1} * 1 * 1 / p_{1}+c_{1} * 0 * 1 / p_{2}\right. \\
& \left.+d_{1} * 0 * 1 / p_{3}\right)+q_{1}=0 \Rightarrow m p_{1}-m c_{1} \\
& =-q_{1} * p_{1} / b_{1} .
\end{aligned}
$$

Hence, for vertical Nash interaction, the vector $\left\{\begin{array}{lll}1 & 0 & 0\end{array}\right\}$ on the left-hand side in the first line of equation $\left(5^{\prime}\right)$ above represents the retailer's (and other manufacturers') interactions with the manufacturer of brand 1 in terms of its price-setting behavior. In other words, this vector captures the nature of the retailer's and other manufacturers' conduct with respect to manufacturer 1. Setting this vector equal to $\left\{\begin{array}{lll}1 & 0 & 0\end{array}\right\}$ corresponds to assuming vertical Nash behavior. Other values of the parameters would represent behavior other than vertical Nash (see discussion below).

Equation (5') also reveals that under the vertical Nash assumption, the manufacturer's margin $\left(m p_{1}-\right.$ $\left.m c_{1}\right)$ is given by $\left(-q_{1}^{*} p_{1} / b_{1}\right)$. Clearly, we expect the margins to vary based on the nature of interactions. To see this, we rewrite equation (5) as

$$
\begin{aligned}
& \left(m p_{1}-m c_{1}\right)=-q_{1} \\
& \quad *\left[b_{1}\left(1+\theta\left(r_{1}, m p_{1}\right)\right) / p_{1}+c_{1}\right. \\
& \left.\quad * \theta\left(p_{2}, m p_{1}\right) / p_{2}+d_{1} * \theta\left(p_{3}, m p_{1}\right) / p_{3}\right]^{-1} .
\end{aligned}
$$

The three $\theta$ parameters- $\theta\left(r_{1}, m p_{1}\right), \theta\left(p_{2}, m p_{1}\right)$, and $\theta\left(p_{3}, m p_{1}\right)$-measure interactions between manufacturer 1 and the retailer and other manufacturer in setting the price of the brand. To understand the implications of these parameters, we examine the effect of the first $\theta$ parameter, $\theta\left(r_{1}, m p_{1}\right)$. This parameter captures the direct interaction of the retailer and manufacturer 1 in determining the price of brand 1. Given a negative own-price effect (i.e., $\left.b_{1}<0\right)$, then for $\theta\left(r_{1}\right.$, $\left.m p_{1}\right) \in(-1,0)$, the manufacturer's margins are higher than those under vertical Nash. At the value zero, the margin equals that in the vertical Nash case. When $\theta\left(r_{1}\right.$, $\left.m p_{1}\right)>0$, the manufacturer's margins fall below the vertical Nash case, and as $\theta\left(r_{1}, m p_{1}\right) \rightarrow \infty$, the manufacturer prices at marginal cost. ${ }^{2}$ When $\theta\left(r_{1}, m p_{1}\right) \in$ $(-1,0)$, we will refer to this as "softer-than-Nash" behavior on the part of the retailer. The reason for this nomenclature is that the retailer is behaving in such a manner that the manufacturer is able to appropriate a higher margin than when the retailer behaves according to vertical Nash.

We would like to clarify that this softer-than-Nash behavior is not the same as "cooperative behavior," as commonly understood in the marketing channels literature. Specifically, cooperative behavior has previously been defined as channel members jointly maximizing profits of the entire channel, and then dividing these profits between the manufacturer and retailer. In our model, each manufacturer maximizes its own profits, and the retailer maximizes category profits over all the manufacturer brands and the private label. Hence, any softer-than-Nash pricing behavior results from realizing the dependence of one's own profit on the profits of the other channel members as well as other manufacturing firms.

The parameters $\theta\left(p_{2}, m p_{1}\right), \theta\left(p_{3}, m p_{1}\right)$ capture both the response of the retailer and the response of the other manufacturers to the price-setting behavior of brand 1 as $\theta\left(p_{j}, m p_{1}\right)=\theta\left(r_{j}, m p_{1}\right)+\theta\left(m p_{j}, m p_{1}\right), j \neq 1$. Therefore, the retailer's interaction with manufacturer $1\left(\theta\left(p_{j}\right.\right.$, $\left.m p_{1}\right)$ ) subsumes the manufacturer $1 \sim$ manufacturer $j$ interaction $\left(\theta\left(m p_{j}, m p_{1}\right)\right)$. In the estimation of the model we will see that this decomposition of the retail price response for other brands to (1) a change in firm 1's pricing into the retailer's response, and (2) the other manufacturer's response cannot be uniquely identified. That is, we can get an estimate of $\theta\left(p_{j}, m p_{1}\right)$ but

\footnotetext{
${ }^{2}$ The $\theta$ parameter can be seen as (scalar, unit-less) multiplier on profit (thanks to Scott Neslin and Don Lehman for this interpretation). Note that we cannot say precisely what competitive game corresponds to any $\theta$ parameter but can tell whether there is a deviation from Betrand Nash pricing. Note also that we cannot provide algebraic bounds for the $\theta$ parameter, unlike several NEIO studies with homogenous products (see Bresnahan 1989).
} 
not of the components $\theta\left(m p_{j}, m p_{1}\right)$ and $\theta\left(r_{j}, m p_{1}\right)^{3}$ Needless to say, this does not mean that we are assuming that $\theta\left(m p_{j}, m p_{1}\right)=0, j=2,3$; i.e., we are not assuming that manufacturer-to-manufacturer interactions are Bertrand-Nash. Because our primary interest in this paper is in measuring manufacturer-retailer channel interactions and the implications for how channel profits are divided between the two parties, it is adequate for the purposes of this study to be able to estimate $\theta\left(p_{i}, m p_{j}\right)$. It is clear from Equation ( $\left.5^{\prime}\right)$ that the manufacturer margin is driven by, among other factors, the composite conduct parameter, $\theta\left(p_{i}, m p_{j}\right)$.

The parameters $\theta\left(r_{1}, m p_{1}\right), \theta\left(p_{2}, m p_{1}\right), \theta\left(p_{3}, m p_{1}\right)$ capture one side of the interactions represented by arrows 2 and 3 in Figure 1. We now turn to the other side of the interaction. In the refrigerated juice category, the retailer is assumed to maximize profits for its private label brands and all national brands (therefore, we do not have an Equation (2) for the private label manufacturer in this category). In the tuna category, the retailer maximizes profits across all national brands. ${ }^{4}$ The retailer's maximand is given by

$$
\pi_{\text {retailer }}=\sum_{i=1}^{3} r_{i}^{*} q_{i}
$$

Note that the cost to the retailer of the product is the manufacturer price. We discuss below the optimization rules for the refrigerated juice category, i.e., where brand 3 is the retailer's private label. It is simple to see from below what the optimization rules look like for tuna with three national brands.

Once again, we first consider the vertical Nash situation. In picking the optimal markup of brand 1, the retailer uses the following optimization rule obtained by differentiating Equation (6) with respect to $p_{1}$ :

$$
\begin{aligned}
q_{1} & +\sum_{j=1}^{3} r_{j}^{*}\left(b_{j}\left(1+\partial m p_{1} / \partial r_{1}\right) * 1 / p_{1}\right. \\
& \left.+c_{j}^{*} \partial m p_{2} / \partial r_{1} * 1 / p_{2}\right)=0 .
\end{aligned}
$$

\footnotetext{
${ }^{3}$ The two components can be estimated separately if they are postulated as functions of market shares, profit shares, demand elasticities, etc. However, such estimation restrictions can distort estimates or can be ad-hoc in nature.

${ }^{4}$ See Karunakaran (1998) for alternative retail maximands including constant margins across brands.
}

Equation (8) restates Equation (7) in the conduct parameter terminology, where the manufacturers' conduct can be represented by the vector $\left\{\theta\left(m p_{1}, r_{1}\right), \theta\left(m p_{2}\right.\right.$, $\left.r_{1}\right)$ :

$$
\begin{aligned}
q_{1} & +\sum_{j=1}^{3} r_{j}^{*}\left(b_{j}\left(1+\theta\left(m p_{1}, r_{1}\right)\right) * 1 / p_{1}\right. \\
& \left.+c_{j}^{*} \theta\left(m p_{2}, r_{1}\right) * 1 / p_{2}\right)=0 .
\end{aligned}
$$

A similar equation is obtained for brand 2 . We note that brand 3 is the private label, and we do not model the interaction between the retailer and the manufacturer of the private label. Setting this vector $\left\{\theta\left(m p_{1}, r_{1}\right.\right.$, $\left.\theta\left(m p_{2}, r_{1}\right)\right\}$ equal to $\{00\}$ corresponds to assuming vertical Nash behavior. Other values of the parameters would represent behavior other than vertical Nash. ${ }^{5}$ For the vertical Nash case, we $\partial m p_{j} / \partial r_{1}=0$ for all $j$, we get

$$
\begin{array}{rl}
r_{1} & *\left(b_{1} / p_{1}\right)+q_{1}+r_{2} *\left(b_{2} / p_{1}\right)+r_{3} \\
& *\left(b_{3} / p_{1}\right)=0 \Rightarrow r_{1} \\
& =-\frac{q_{1}+r_{2} *\left(b_{2} / p_{1}\right)+r_{3} *\left(b_{3} / p_{1}\right)}{b_{1} / p_{1}} .
\end{array}
$$

As noted previously, $\theta\left(p_{i}, m p_{j}\right)$, and specifically, $\theta\left(r_{i}\right.$ $\left.m p_{j}\right), i=1,2,3 ; j=1,2$ capture part of the interaction between manufacturers and the retailer, i.e., along arrows 2 and 3. The other part of the interaction between manufacturer 1 and the retailer is the effect that manufacturer's pricing of brand 1 on retailer's profits. In general, the parameters $\theta\left(m p_{j}, r_{i}\right), i=1,2,3 ; j=1,2$ along with those described earlier (i.e., $\theta\left(p_{i}, m p_{j}\right)$ ) characterize the interaction between manufacturers and the retailer (i.e., along arrows 2 and 3 in Figure 1). Furthermore, if $\theta\left(m p_{j}, r_{i}\right) \neq \theta\left(r_{i}, m p_{j}\right)$, then the nature of interactions between the channel members is asymmetric. In the empirical analysis we allow for this asymmetry.

To focus on interactions between the retailer and manufacturer 1 in the general case, we see from Equation (8) above that the retailer's profits come from three different sources: profits on brands 1, 2, and 3; i.e., rewriting Equation (8) we get

\footnotetext{
${ }^{5}$ Other restricted behaviors can also be tested, e.g., with $\theta\left(r_{i}, m p_{i}\right)=$ 0 , or symmetry in manufacturer behavior interactions, i.e., equal $\theta\left(m p_{i}, r_{i}\right)$ for all $i$, and $\theta\left(m p_{i}, m p_{j}\right)$ for all $i, j$.
} 


$$
\begin{aligned}
r_{1}= & {\left[-q_{1}-\sum_{j \neq 1} r_{j} *\left(b_{j}\left(1+\theta\left(m p_{1}, r_{1}\right)\right)\right.\right.} \\
& \left.\left.* 1 / p_{1}+c_{j} \theta\left(m p_{2}, r_{1}\right) * 1 / p_{2}\right)\right] \\
& *\left[\left(b_{1}\left(1+\theta\left(m p_{1}, r_{1}\right)\right)\right.\right. \\
& \left.\left.* 1 / p_{1}+c_{1} \theta\left(m p_{2}, r_{1}\right) * 1 / p_{2}\right)\right]^{-1} .
\end{aligned}
$$

Similarly for brands 2 and 3, we have

$$
\begin{aligned}
r_{2}=\left[-q_{2}-\sum_{j \neq 2} r_{j} *\left(b_{j} \theta\left(m p_{1}, r_{2}\right)\right.\right. \\
* 1 / p_{1}+c_{j}\left(1+\theta\left(m p_{2}, r_{2}\right)\right) \\
\left.\left.* 1 / p_{2}\right)\right] *\left[\left(b_{2} \theta\left(m p_{1}, r_{2}\right)\right.\right. \\
\left.\left.* 1 / p_{1}+c_{2}\left(1+\theta\left(m p_{2}, r_{2}\right)\right) * 1 / p_{2}\right)\right]^{-1}, \\
r_{3}=\left[-q_{3}-\sum_{j \neq 3} r_{j} *\left(b_{j} \theta\left(m p_{1}, r_{3}\right)\right.\right. \\
* 1 / p_{1}+c_{j} \theta\left(m p_{2}, r_{3}\right) * 1 / p_{2}+d_{j} \\
\left.\left.* 1 / p_{3}\right)\right] *\left[\left(b_{3} \theta\left(m p_{1}, r_{3}\right)\right.\right. \\
* 1 / p_{1}+c_{3} \theta\left(m p_{2}, r_{3}\right) \\
\left.\left.* 1 / p_{2}+d_{3} * 1 / p_{3}\right)\right]^{-1} .
\end{aligned}
$$

To obtain the retailer markups $r_{1}, r_{2}$, and $r_{3}$, we need to solve Equations (9) through (11) simultaneously. This would imply that the markup on any brand, say $r_{1}$, would be a function of all the conduct parameters. Specifically,

(1) The conduct of the manufacturer of brand 1 visà-vis the retailer's margins for the three brands, i.e., $\theta\left(m p_{1}, r_{j}\right), j=1,2,3$.

(2) The conduct of the other manufacturer vis-à-vis the retailer's margins for the three brands, i.e., $\theta\left(m p_{2}\right.$, $\left.r_{j}\right), j=1,2$, and 3 .

An important implication that becomes evident from (1) and (2) above is that the retailer's markup on any brand $j(j=1,2,3)$ depends not only on its interaction with the manufacturer of brand $j$, but also on its interaction with the manufacturers of the other brands. Hence, what we have is a flexible model of market interaction. By estimating the conduct parameters we can determine empirically if such dependencies exist in any given situation.

To isolate the interaction between manufacturer 1 (say) and the retailer, the interest is on the set of the three parameters $\theta\left(m p_{1}, r_{j}\right), j=1,2,3$. Recall that for the vertical Nash case all three parameters are zero. In general, the magnitudes of these three parameters will determine whether the interaction leads to a margin $r_{1}$ for brand 1 being larger or smaller than the vertical Nash case. To see if this manufacturer is pricing softerthan-Nash or competitively, we do the following: (1) set these three parameters to zero, and keep all other manufacturer parameters at their estimated value (this gives us the retailer's margins if this manufacturer is behaving Nash); (2) compare these margins to the margins that the retailer makes with the estimated manufacturer conduct parameters (i.e., those from data), and if the calculated data margins are larger than those calculated in step 1, then the manufacturer is pricing softer-than-Nash; if the calculated data margins are smaller than those from step 1, this manufacturer is pricing more competitively than Nash. The nature of the interactions between the other manufacturers and the retailer can be uncovered in a similar manner.

2.2.3. The Relationship Between Competitive Interactions and Power in the Channel. As described in the above two sections, we can determine the nature of competitive interactions between manufacturers and retailers. To measure channel performance, we measure how channel profits are split between manufacturer and retailer. These channel profit shares are calculated, for each retailer-manufacturer $i$ pair as follows:

Channel profits for retailer from brand $i$ for any week $\left(p_{i}-m p_{i}\right) * q_{i}=r_{i}^{*} q_{i}$

Channel profit for manufacturer $i$ for any week $=\left(m p_{i}\right.$ $\left.-m c_{i}\right)^{*} q_{i}$.

Therefore, share of channel profits for the manufacturer over the entire period of observation:

$$
\begin{aligned}
S C \pi_{m} & =\sum_{t=1}^{T} \frac{\left(m p_{i t}-m c_{i t}\right) * q_{i t}}{\left(p_{i t}-m p_{i t}\right) * q_{i t}+\left(m p_{i t}-m c_{i t}\right) * q_{i t}} \\
& =\sum_{t=1}^{T} \frac{\left(m p_{i t}-m c_{i t}\right) * q_{i t}}{\left(p_{i t}-m c_{i t}\right) * q_{i t}} .
\end{aligned}
$$

Share of channel profits for retailer:

$$
\begin{aligned}
S C \pi_{r} & =\sum_{t=1}^{T} \frac{\left(p_{i t}-m p_{i t}\right) * q_{i t}}{\left(p_{i t}-m p_{i t}\right) * q_{i t}+\left(m p_{i t}-m c_{i t}\right) * q_{i t}} \\
& =\sum_{t=1}^{T} \frac{\left(p_{i t}-m p_{i t}\right) * q_{i t}}{\left(p_{i t}-m c_{i t}\right) * q_{i t}}=\sum_{t=1}^{T} \frac{r_{i t}^{*} q_{i t}}{\left(p_{i t}-m c_{i t}\right) * q_{i t}} .
\end{aligned}
$$


Therefore, higher the share of profits a manufacturer has in the channel interaction with the retailer, the greater is its power. (The marginal cost parameter for manufacturer $i\left(m c_{i}\right)$ is estimated from the data.) To provide further insights in to why the channel profits are split the way they are, we relate the estimated competitive conduct (via the conduct parameters) to market performance (share of channel profits) and the estimated demand and marginal cost parameters.

Consider as an illustration Equation (9):

$$
\begin{aligned}
r_{1}= & {\left[-q_{1}-\sum_{j \neq 1} r_{j} *\left(b_{j}\left(1+\theta\left(m p_{1}, r_{1}\right)\right)\right.\right.} \\
& \left.\left.* 1 / p_{1}+c_{j} \theta\left(m p_{2}, r_{1}\right) * 1 / p_{2}\right)\right] \\
& *\left[\left(b_{1}\left(1+\theta\left(m p_{1}, r_{1}\right)\right)\right.\right. \\
& \left.\left.* 1 / p_{1}+c_{1} \theta\left(m p_{2}, r_{1}\right) * 1 / p_{2}\right)\right]^{-1} .
\end{aligned}
$$

The retailer's power in pricing brand 1 is driven by its margin $r_{1}$ on that brand (divided by retail pricemanufacturer's marginal cost). This margin is obtained from data on retail and manufacturer prices. Pricing power is related to how competing manufacturers 1 and 2 price their respective brands in response to the retailer setting the retail price of brand 1 . This is measured by the $\theta$ parameters in the above equation. The retailer's markup $r_{1}$ on brand 1 is also related to ownand cross-price effects for brand 1 as a result of the presence of the parameters $b_{1}, b_{2}$, and $b_{3}$. Therefore, in explaining the computed pricing power, we appeal to the estimates of demand, costs, and competitive conduct.

\subsection{Relationship Between the General Model and Specific Theoretical Models}

The purpose of building the general, estimable model of channel power or pricing games or vertical arrangements in $\$ 2.2$ was to account for a variety of possible such arrangements and not confine ourselves to the ones existing in the theoretical literature, for the reasons given previously. The set of conduct $(\theta)$ parameters in the above equations include a variety of possible strategic behaviors on the part of manufacturers and retailers. To see this, we first rewrite equations $\left(5^{\prime \prime}\right)$ and (9):

$$
\begin{aligned}
m p_{1}= & m c_{1}+\left[-q_{1}\right] *\left[b_{1} *\left(1+\theta\left(r_{1}, m p_{1}\right)\right) / p_{1}+c_{1}\right. \\
& \left.* \theta\left(p_{2}, m p_{1}\right) / p_{2}+d_{1} * \theta\left(p_{3}, m p_{1}\right) / p_{3}\right]^{-1},
\end{aligned}
$$

$$
\begin{aligned}
m p_{2}= & m c_{2}+\left[-q_{2}\right] *\left[b_{2} * \theta\left(p_{1}, m p_{2}\right) / p_{1}+c_{2}\right. \\
& \left.*\left(1+\theta\left(r_{2}, m p_{2}\right)\right) / p_{2}+d_{2} * \theta\left(p_{3}, m p_{2}\right) / p_{3}\right]^{-1}, \\
r_{1}= & {\left[-q_{1}-\sum_{j \neq 1} r_{j}^{*}\left(b_{j}\left(1+\theta\left(m p_{1}, r_{1}\right)\right)\right.\right.} \\
& \left.\left.* 1 / p_{1}+c_{j} \theta\left(m p_{2}, r_{1}\right) * 1 / p_{2}\right)\right] \\
& *\left[\left(b_{1}\left(1+\theta\left(m p_{1}, r_{1}\right)\right) * 1 / p_{1}+c_{1} \theta\left(m p_{2}, r_{1}\right)\right.\right. \\
& \left.\left.* 1 / p_{2}\right)\right]^{-1} .
\end{aligned}
$$

From the optimization rules above, we have a total of $12\left(=3^{*} 2+2^{*} 3\right)$ conduct parameters. These can be summarized as follows by an extension of Figure 1.

Arrow (1) is captured by the parameter $\theta\left(m p_{2}, m p_{1}\right)$ (not identified separately in the model), arrow (2) corresponds to $\theta\left(m p_{1}, m p_{2}\right)$ (also not identified separately in the model). Arrow 3 is captured by $\theta\left(m p_{1}, r_{1}\right), \theta\left(m p_{1}\right.$, $\left.r_{2}\right)$ and $\theta\left(m p_{1}, r_{3}\right)$. Arrow 4 comprises $\theta\left(r_{1}, m p_{1}\right), \theta\left(r_{2}\right.$, $\left.m p_{1}\right)$, and $\theta\left(r_{3}, m p_{1}\right)$. Arrows 5 is similar to arrow 4 , and arrow 6 is similar to arrow 3 .

If the interaction between the manufacturers and the retailer is vertical Nash, then all 12 conduct parameters $=0$, and the equations reduce (for general i) to

$$
\begin{aligned}
m p_{i}= & m c_{i}-\frac{q_{i}^{*} p_{i}}{n_{i}} \text { for } i=1,2 \\
& \text { where } n=b \text { for } i=1, n=c \text { for } i=2, \\
r_{i}= & -\frac{q_{i}}{n_{i} / p_{i}}-\frac{\sum_{j \neq i} r_{j}^{*} n_{j} / p_{j}}{n_{i} / p_{i}} \text { for } i=1,2,3 .
\end{aligned}
$$

Hence, the case of Nash interactions is nested within the general model. If the interactions are non-Nash, we can also infer whether or not the channel members are behaving more or less competitively than Bertrand pricing toward one another based on the values of the $\theta$ parameters. Hence, if we estimate these $\theta$ parameters from the data, we will be able to infer the nature of channel interactions.

Unlike the vertical Nash case and the softer-thanNash/more-competitive-than-Nash cases above, the cases of Stackelberg leader-follower, with the manufacturer being either the leader or the follower, are not nested within the general model specified above. Therefore, if we want to determine whether or not channel interactions correspond to a Stackelberg 
leader-follower game, we would have to do the following. For the game where manufacturers are Stackelberg leaders relative to the retailer and interacting Bertrand-Nash with each other, the BertrandNash retailer conditions above are solved to obtain retail prices as function of manufacturer prices. These functions are inserted in the manufacturer optimization rules and the optimum manufacturer prices are obtained under the condition that all intermanufacturer interactions are Bertrand-Nash (see Choi 1991 for details).

We then perform a test of nonnested hypotheses to determine which model of channel interaction (Stackelberg leader $\sim$ follower or the proposed general model) is more consistent with data. If the data reject the manufacturer-Stackelberg model in favor of our proposed model, we infer the nature of channel interactions based on the interpretation of the estimated $\theta$ parameters. If the reverse is true, then it implies that the data are (more) consistent with the manufacturerStackelberg model. Once again, we would have inferred the nature of channel interactions. In a similar fashion, we can investigate the retailer-Stackelberg model.

An interesting feature is that for some of these games, data on retail prices alone (i.e., without data on manufacturer prices) are sufficient to estimate the competitive game. Examples include Nash or simultaneous pricing (as done by Besanko et al. 1999), or a leaderfollower game with the manufacturer being the price leader (as done by Karunakaran 1998). However, it is not possible to estimate the general game above without the manufacturer prices for the national brands. Our interest in this paper is to estimate the parameters of the general model that can account for a variety of possible pricing games. Combining this insight with the discussion in $\$ 2.2$, we see that if the data reject the Nash specification as well as the retailer or manufacturer Stackelberg leader model, the general model can tell us whether retailers are pricing more or less competitively than vertical Nash. Further, as noted previously, the manufacturer-to-manufacturer game cannot be uniquely identified by the data because those conduct parameters are subsumed within the retailer's interaction with each manufacturer.

\subsection{Estimation}

The system of estimating equations is obtained from the demand equations and the first-order conditions for manufacturers' prices and the retailer's retail prices. ${ }^{6}$ For refrigerated juice, we have two national brands and one private label brand. Hence, we have three demand equations, two manufacturer pricing equations (because we do not model the producer of the private label brand), and three retailer pricing equations, for a total of eight equations. For the tuna product category, we have three demand, three manufacturer equations (because there is no private label brand), and three retailer equations, for a total of nine equations. For the refrigerated juice category, the estimating equations are as follows.

\section{Demand equations:}

$$
\begin{aligned}
q_{i} & =a_{i}+b_{i} * \ln \left(p_{1}\right)+c_{i} * \ln \left(p_{2}\right)+d_{i} * \ln \left(p_{3}\right) \\
& +g_{i} * \text { ddshifter }+h_{i} * \operatorname{deal}_{i}+\varepsilon_{i} \quad i=1,2,3 .
\end{aligned}
$$

The manufacturers' optimal price rules (Equations (12) and (13)):

$$
\begin{aligned}
& m p_{1}=m c_{1}+\left[-q_{1}\right] *\left[b_{1} *\left(1+\theta\left(r_{1}, m p_{1}\right)\right) / p_{1}+c_{1}\right. \\
& \left.* \theta\left(p_{2}, m p_{1}\right) / p_{2}+d_{1} * \theta\left(p_{3}, m p_{1}\right) / p_{3}\right]^{-1}+\varepsilon_{4} \\
& m p_{2}=m c_{2}+\left[-q_{2}\right] *\left[b_{2} * \theta\left(p_{1}, m p_{1}\right) / p_{1}+c_{2}\right. \\
& \left.*\left(1+\theta\left(r_{2}, m p_{1}\right)\right) / p_{2}+d_{2} * \theta\left(p_{3}, m p_{1}\right) / p_{3}\right]^{-1}+\varepsilon_{5} .
\end{aligned}
$$

The retailer's optimal price rules (Equations (14), (15), and (16)):

$$
\begin{aligned}
r_{1}= & {\left[-q_{1}-\sum_{j \neq 1} r_{j} *\left(b_{j}\left(1+\theta\left(m p_{1}, r_{1}\right)\right)\right.\right.} \\
& \left.\left.* 1 / p_{1}+c_{j} \theta\left(m p_{2}, r_{1}\right) * 1 / p_{2}\right)\right] \\
& *\left[\left(b_{1}\left(1+\theta\left(m p_{1}, r_{1}\right)\right) * 1 / p_{1}+c_{1} \theta\left(m p_{2}, r_{1}\right)\right.\right. \\
& \left.\left.* 1 / p_{2}\right)\right]^{-1}+\varepsilon_{6},
\end{aligned}
$$

${ }^{6}$ Note that all the conduct parameters are identified without restrictions. For a category with more brands, it is likely that more data points will be needed to be able to estimate the additional parameters. Alternatively, we can impose some estimation restrictions. 


$$
\begin{aligned}
r_{2}= & {\left[-q_{2}-\sum_{j \neq 2} r_{j} *\left(b_{j} \theta\left(m p_{1}, r_{2}\right)\right.\right.} \\
& \left.\left.* 1 / p_{1}+c_{j}\left(1+\theta\left(m p_{2}, r_{2}\right)\right) * 1 / p_{2}\right)\right] \\
& *\left[\left(b_{2} \theta\left(m p_{1}, r_{2}\right) * 1 / p_{1}+c_{2}\left(1+\theta\left(m p_{2}, r_{2}\right)\right)\right.\right. \\
& \left.\left.* 1 / p_{2}\right)\right]^{-1}+\varepsilon_{7}, \\
r_{3}= & {\left[-q_{3}-\sum_{j \neq 3} r_{j} *\left(b_{j} \theta\left(m p_{1}, r_{3}\right)\right.\right.} \\
& \left.\left.* 1 / p_{1}+c_{j} \theta\left(m p_{2}, r_{3}\right) * 1 / p_{2}+d_{j}^{*} 1 / p_{3}\right)\right] \\
& *\left[\left(b_{3} \theta\left(m p_{1}, r_{3}\right) * 1 / p_{1}+c_{3} \theta\left(m p_{2}, r_{3}\right)\right.\right. \\
& \left.\left.* 1 / p_{2}+d_{3} * 1 / p_{3}\right)\right]^{-1}+\varepsilon_{8} .
\end{aligned}
$$

The error terms $\left(\varepsilon_{1}, \varepsilon_{2}, \varepsilon_{3}, \varepsilon_{4}, \varepsilon_{5}, \varepsilon, \varepsilon_{6}, \varepsilon_{7}, \varepsilon_{8}\right)$ in the above eight equations are the econometrician's error, i.e., they capture the effects of random demand and supply-side effects. The error terms are contemporaneously correlated although assumed to be serially uncorrelated. The demand system error terms can be interpreted as stemming from brand specific temporal shocks; the error terms in the price equations could be a result of either demand shocks or cost shocks or both. We assume that that the errors are not the result of mispecification of demand, cost, or firm behavior. (We perform some specification tests to ensure this; see section 4.1. ${ }^{7}$ We also assume that these errors do not arise from firms not having full information about each other.

Finally, we note that all the $\theta$ parameters are identified and can be estimated from the data. We also note that for the refrigerated juice category with two manufacturer brands and one private label brand, we have a total of 12 conduct $(\theta)$ parameters. For the tuna category with all three brands considered being manufacturer brands, we have a total of 18 conduct parameters. As mentioned previously, the difference between the two categories is that in the case of refrigerated juice,

\footnotetext{
${ }^{7}$ These assumptions can be relaxed in at least two ways. First, richer error properties can be accounted for in estimation, especially timeseries error properties. Second, the first-order conditions can be seen as sample analogues of the first-order conditions, and GMM estimation can be used.
}

we treat the producer of the private label as being passive. We emphasize, however, that we do treat the manufacturer price of the private label as being endogenous in the econometric estimation of the model parameters.

\section{Data and Estimation Issues}

\subsection{Description of the Data}

The data are weekly data for Dominick's Finer Foods, one of the two largest retail chains in Chicago metropolitan market area. The data are aggregated across all stores in the retail chain and are for the time period 9/ 14/89-11/25/93, i.e., 218 weeks. In refrigerated juice, the three brands account for $89 \%$ of the market; in tuna, the three brands account for $80 \%$ market share. In refrigerated juice, the brands are Tropicana, MinuteMaid, and the private label. The tuna brands are Chicken of the Sea (COS), Starkist, and Bumble Bee.

The variables in the dataset are the following.

(1) Retail price, calculated as a weighted average price across UPCs and sizes in any one brand.

(2) Manufacturer price, calculated from the data on cents margin per brand by UPC.

(3) Quantity, in ounces. This implies that we are not studying product size as a variable in competition.

(4) Outside sales in category, which measures the sales in this product category across all stores in the market not including this chain. We were concerned that, given that this variable captures retail competition, it might be endogenous. ${ }^{8}$ We tested for the exogeneity of this variable, and it is indeed exogenous. This test of exogeneity is done as follows. We estimate the demand and pricing system of equations as described in \$2.4. To test for the endogeneity of this variable, we follow the Spenser and Berk (1981) test as described in Green (1990). This involves comparing estimates of each demand equation by 2SLS treating this variable as exogenous and endogenous. The test statistic is based on the difference between the two estimators and is a Wald statistic. We are unable to reject the null of exogeneity of the outside sales in category variable $\left(\chi^{2}\right.$,

\footnotetext{
${ }^{8}$ The presence of retail competition ensures that the retailer does not extract all profit from manufacturers, e.g., through a two-part pricing scheme (as in Coughlan and Wernerfelt 1988).
} 
KADIYALI, CHINTAGUNTA, AND VILCASSIM

An Empirical Investigation of Pricing in a Local Market

two degrees of freedom, table value $=5.99$ at $95 \%$, and calculated value $=1.224$ ). Therefore, this variable serves as a demand shifter for our study.

(5) Deal, calculated as percentage of UPCs in the brand which are on deal during the week.

We supplement those data with the following variables.

(1) Summer dummy, for weeks after Easter to the week before Labor Day. There might be possibly higher demand for refrigerated juice (less likely to be relevant for tuna). Hence, we use this as an exogenous demand variable.

(2) Wages, the city area wages data from The Bureau of Labor Statistics. These data are given by quarter. We assume that the quarterly value applies to each week in the quarter.

(3) Consumer Price Index for the Midwest region (the index is set $=100$ for week 1), also obtained from the Bureau of Labor Statistics. These data are also available by quarter. This index is used to deflate both retail and manufacturer price and the wage series. ${ }^{9}$ Therefore, we use the regional CPI to deflate the regional price series. Tables $1 \mathrm{a}$ and $1 \mathrm{~b}$ give descriptive statistics for these variables for each category

We would like to describe how these data enable the estimation of manufacturer-retailer interactions. First, consider the geographic coverage of the data. Aggregating data to the national (USA) level may well fail to capture the important idiosyncrasies of both the specific product market as well as the role of the retailer in a given local market. There are two reasons for this. First, the nature of the competition among manufacturers will vary across different product markets for a variety of possible reasons, including differences in their identities and competitive positions, the nature of the customer buying behavior, and other demand and/or supply conditions. Second, in a country like the United States, in which there are no national supermarket retailers yet, the role of a given retailer is confined largely to either a local or regional level. Furthermore, competition faced by the national brand manufacturers from private label brands is not likely

${ }^{9}$ The Wholesale Price Index is more appropriate for deflating the manufacturer prices, but these series are unavailable for the relevant city area.
Table 1a Descriptive Statistics for Variables for Refrigerated Juice

\begin{tabular}{lrr}
\hline Variable & (Weekly) Mean & Std. Dev. \\
\hline MinuteMaid quantity (ozs) & 2509117 & 1987285 \\
Tropicana quantity & 3534684 & 3056136 \\
Private label quantity & 2743927 & 2205164 \\
MinuteMaid (percentage UPCs & & \\
$\quad$ on deal ${ }^{* 100)}$ & 1323 & 1612 \\
Tropicana on deal & 1595 & 1605 \\
Private label on deal & 1821 & 1799 \\
Demand shifter (dollars) & 1907729 & 159142 \\
Wage (dollars) & 22153 & 2891 \\
CPI (index) & 108.81 & 4.32 \\
MinuteMaid retail price (cents per 0z) & 2.74 & 0.48 \\
Tropicana retail price & 3.36 & 0.58 \\
Private label retail price & 2.06 & 0.40 \\
MinuteMaid manufacturer price (cents per 0z) & 2.00 & 0.33 \\
Tropicana manufacturer price & 2.46 & 0.38 \\
Private label manufacturer price & 1.43 & 0.30 \\
\hline
\end{tabular}

Table 1b Descriptive Statistics for Variables for Tuna

\begin{tabular}{lcr}
\hline Variable & (Weekly) Mean & Std. Dev. \\
\hline Chicken of the Sea quantity (oz) & 202500 & 399465 \\
Starkist quantity & 225281 & 73105 \\
BumbleBee quantity & 141449 & 165255 \\
Chicken of the Sea on deal (\% UPCs & & \\
$\quad$ on deal ${ }^{*}$ 100) & 386 & 1116 \\
Starkist on deal & 616 & 1133 \\
BumbleBee on deal & 683 & 1328 \\
Demand shifter (dollars) & 1911533 & 161529 \\
Chicken of the Sea retail price (cents per 0z) & 12.15 & 1.99 \\
Starkist retail price & 13.96 & 1.91 \\
BumbleBee retail price & 14.65 & 2.91 \\
Chicken of the Sea manufacturer price & 9.49 & 1.60 \\
Starkist manufacturer price & 10.70 & 1.30 \\
BumbleBee manufacturer price & 10.84 & 2.10 \\
\hline
\end{tabular}

to be of equal intensity across different markets because of differences in the nature and quality of the private label brands. Hence, an analysis of manufacturer-retailer interactions based on highly aggregate data is not likely to yield as meaningful insights compared to analyzing a specific product category in a local or regional market. Therefore, having data for a local market is necessary to study manufacturer-retailer channel games and power issues. 
Another positive aspect to our dataset is the availability of manufacturer price series. Traditionally, such data are very hard to obtain. In their study of competition between national and private brands, Connor and Peterson (1992) state, "Perhaps the most serious limitation is that price margins used in this paper are retail-level price differences. Therefore, the margins include the gross margins of national manufacturers, wholesalers, and retailers." This means that the authors' conclusion about competition between national and private labels based on retail prices may not be accurate. For greater accuracy, the authors would have to compare manufacturer and retail prices of national brands relative to manufacturer and retail prices of private labels.

Cotterill et al. (1997) also estimate price-setting behavior of private label and national brands. However, because of lack of data on manufacturer prices, they assume that national manufacturers set the retail prices of national brands, and the retail price of the private label brand is set by the retailer. This is also the assumption made by Parker and Kim (1996), who examine competition in pricing and advertising between private label and national brands. In the Parker-Kim paper, too, it is not possible to estimate a channel game between manufacturers and retailers because of lack of data on manufacturer prices. Another proposed solution to the problem of lack of manufacturer data is that by Narasimhan and Wilcox (1996), who estimate retail markups (or equivalently, manufacturer prices) from the 1991 Annual Consumer Expenditure Survey of the Supermarket Business as an approximation to obtaining actual markups from retailers. However, such a measure would be inadequate when weekly data are used in the estimation of the other model parameters.

A feature of the manufacturer price series is that promotional allowances are factored in to the cost of goods for retailers when they are sold by the retailer rather than when they are sold to the retailer. Therefore, the weekly price series reflect the effective manufacturer price that week. However, Stern et al. (1996) list a variety of other costs that national firms incur when dealing with retailers, e.g., slotting allowances, buy-back charges, failure fees, etc. We do not have data on these cost drivers. If we did, Equation (2) could be modified to include all these costs. If these costs are fixed costs, they would drop out of the optimization rules. If there are other variables costs for the manufacturer, our results will overstate the manufacturer's profit share and their channel power. Similarly, retailers may have other variables costs outside of the manufacturer price series that we cannot estimate in our model (this variable cost would not be identified separately from the manufacturer price in the retailer pricing equations; see Borin and Farris 1990 for a discussion of some of these costs). Therefore, failing to account for these other variable costs of the retailer would overstate the profit share of the retailer, in our estimation. Of course, fixed costs for retailers are also not included in the analysis. Therefore, the measure of power in our model is a division of channel variable profits only, subject to the caveats about what the data series actually capture.

\subsection{Decision Making Timeframe}

We assume that all manufacturers and the retailer make pricing decisions every week. Because retailers typically announce prices on a weekly basis, assuming a weekly time horizon for the retailer is appropriate. However, that may not be the case for the national brand manufacturers. If we assume that firms are making decisions once a month and retailers every week, we would have to estimate the optimization rules for the manufacturers at the monthly level, and for the retailer at the weekly level. In estimating these monthly rules, manufacturers will need to make assumptions about the retailer's pricing decisions for the weeks following the week in which the manufacturer makes its monthly pricing decision. Similarly, for the retailer, the manufacturer price would be endogenous only at the start of every monthly manufacturer decision-making cycle, and exogenous after that. These issues pose very serious modeling and estimation problems. Therefore, we assume for simplicity that firms and retailers have the same decision-making cycle. Additionally, given the large number of parameters to be estimated in the system and the relatively small number of data points, we prefer to let the decision making cycle be every week rather than every month. In this timeframe, the manufacturers' decisions can be interpreted as weekly realizations of their monthly pricing rules. 
If manufacturers indeed set their prices once a month or less frequently, we would expect to find little variance in weekly manufacturer prices. This is not the case in our data. As mentioned previously, the manufacturer price series are the effective manufacturer prices reported by the retailer, and given that products bought on promotion by the retailer may be sold by the retailer over several weeks, this variance in weekly prices is not surprising. We also tested for the endogeneity of these manufacturer weekly prices, and they are indeed endogenous (the same test as described in \$3.1; the null hypothesis of exogeneity was rejected at 95\% confidence for each manufacturer price series). Therefore, using weekly data does not pose a problem and is appropriate for our purpose.

\subsection{Other Estimation Issues}

We estimate the system of eight (refrigerated juice)/ nine (tuna) equations in \$2.4, consisting of the demand Equation (3); manufacturer price rules (two for refrigerated juice, three for tuna); and retailer retail price rules (3) using the 3SLS procedure in SAS. Usually, instrumental variables are exogenous demand and cost shifters, and if there are no dynamics in the model, lagged values of dependent variables. The exogenous instrumental variables we used are current and lagged (10 time periods) wages, summer dummies, and the outside sales in category variable. We experimented with a variety of lagged dependent variables and found that the lagged deal variable performed best as an instrumental variable. Hence, we report results using current and lagged wages, summer dummies, and lagged deal variables, as well as the exogenous demand and cost shifters.

As noted in §2, the deal variable in the demand function is determined jointly by manufacturers and retailers. This variable, too, cannot be treated as exogenous in the estimation process. Therefore, we treat them as endogenous variables in the instrumental variable step.

Another feature of the estimation is that we had to experiment with the exogenous demand variable. In various runs, we found wages to be insignificant, which may not be surprising given that this is not a product category where we would expect a significant variance in demand as wages vary. Based on various estimation runs with the seasonal dummies, the demand shifter we used in the final model was just the outside sales of the category. The seasonal dummies turn out to be insignificant for both the tuna and refrigerated juice categories.

\section{Results}

In this section we first compare the model fits for the proposed formulation and the vertical Nash, manufacturer leader, and manufacturer follower pricing games. Next, we discuss the estimates obtained from the best-fitting model and discuss the implications of this model for channel interactions and the division of channel profits.

\subsection{Comparing the Different Model Specifications} We estimate the system of demand and manufacturer and retailer optimization equations listed in \$2.4 using the 3SLS procedure in SAS. Additionally, we estimate the parameters of the systems corresponding to three Choi channel structures. Table 2 reports the minimized sum of squared errors corresponding to these four games for the two product categories. To ensure that there is no misspecification in our model, we perform a Hausman (1981) test, where the 2SLS and 3SLS estimates of demand functions are compared. This test ensures that there is no misspecification in the first-order conditions. Under the null hypothesis of no misspecification, both 2SLS and 3SLS estimates are consistent and unbiased. Under the alternative hypothesis of misspecification, 2SLS is unbiased, but 3SLS is biased because the misspecification in the first-order conditions spreads through to the demand-function estimates (see Green 1990 for details). For the refrigerated juice category, we cannot reject the null of no misspecification, and we find similar results for the tuna category. ${ }^{10}$

Table 2 also shows that the (nested) vertical Nash game is rejected in favor of the best-fitting game. The (nonnested) game where the manufacturer leads the retailer in price-setting and the (nonnested) game where the retailer leads the manufacturer in pricesetting have higher sums of squared errors for both

${ }^{10} \chi^{2}$, six degrees of freedom, for each demand function, table value $=12.59$ at $95 \%$. Calculated values for juice are $7.39,4.34$, and 5.35 for brands 1, 2, and 3, respectively; for tuna $=4.75,8.32$, and 6.9 for brands 1,2 , and 3 respectively. 
KADIYALI, CHINTAGUNTA, AND VILCASSIM

An Empirical Investigation of Pricing in a Local Market

Table 2a Model Fit Statistics of Some Games for Refrigerated Juice

\begin{tabular}{|c|c|c|}
\hline Model & Sum of Squared Errors & Test Statistic: Critical (95\%) and Estimated Value \\
\hline Proposed specification & 473.6229 & \\
\hline Vertical Nash (nested in the proposed model) & 584.3961 & $\begin{array}{l}\text { - } \chi^{2}(12 \text { degrees of freedom }) \text { critical value }=21.03 \\
\text { - Difference in estimated sums of squared errors }=110.77\end{array}$ \\
\hline Manufacturer Stackelberg leader (not nested in the proposed model) & 659.6251 & $\begin{array}{l}-V \text { critical value }=1.64 \\
\text { - The estimated value }=5.83\end{array}$ \\
\hline Retailer Stackelberg leader (not nested in the proposed model) & 514.62 & $\begin{array}{l}\text { - } V \text { critical value }=1.64 \\
\text { - Estimated one }=3.54\end{array}$ \\
\hline
\end{tabular}

Table 2b Model Fit Statistics of Some Games for Tuna

\begin{tabular}{|c|c|c|}
\hline Model & Sum of Squared Errors & Test Statistic: Critical (95\%) and Estimated Value \\
\hline Proposed specification & 682.14 & \\
\hline Vertical Nash (nested in the proposed model) & 811.99 & $\begin{array}{l}\text { - } \chi^{2}(18 \text { degrees of freedom }) \text { critical value }=28.87 \\
\text { - Difference in estimated sums of squared errors }=129.86\end{array}$ \\
\hline Manufacturer Stackelberg leader (not nested in the proposed model) & 809.61 & $\begin{array}{l}-V \text { critical value }=1.64 \\
\text { - The estimated value }=4.47\end{array}$ \\
\hline Retailer Stackelberg leader (not nested in the proposed model) & 701.90 & $\begin{array}{l}\text { - } V \text { critical value }=1.64 \\
\text { - The estimated value }=1.88\end{array}$ \\
\hline
\end{tabular}

product categories. Therefore, it appears prima facie that the proposed model describes the channel interactions better than the other three models for each product category. The Vuong (1989) test can be used to compare nonnested hypotheses. The test statistic is given by

$$
V=\frac{1}{\sqrt{n}}\left\{\operatorname{Ln}\left[\frac{f}{g}\right]-(p-q)\right\},
$$

where $n=$ number of observations, $f$ and $g$ are likelihood values of the two nonnested models, and $p$ and $q$ are the number of parameters estimated in each model, respectively. $V$ is distributed $N(0,1)$. Note that $f$ can be greater or lesser than $g$. This means that computed $V$ can be positive or negative. If $V$ is $>0$ and $V$ is $>V$ (critical value), then the model corresponding to $g$ is rejected in favor of the model corresponding to $f$ and vice-versa.

To implement the test, we compute the likelihood value for the proposed model and the two Stackelberg specifications. The calculated value of the test-statistic $V$ and the critical values are listed in Tables $2 \mathrm{a}$ and $2 \mathrm{~b}$.
Based on those values, we reject the two Stackelberg specifications in favor of the proposed model for both product categories. In the subsequent discussion we refer to our proposed model as the "best-fitting model."

\subsection{What Does the Best-Fitting Game Mean?}

The estimates of the best-fitting game are in Tables 3a and $3 b$ for the refrigerated juice and tuna categories, respectively. In Tables $4 \mathrm{a}$ and $4 \mathrm{~b}$ we report the computed channel profit shares for the manufacturers and the retailer (computed as per Equation (12)). In Tables $5 \mathrm{a}$ and $5 \mathrm{~b}$ we report the computed price elasticities for the two categories. We examine first the results for the refrigerated juice category, followed by those for the tuna category.

\subsubsection{Channel Interactions in Refrigerated} Juice. Let us first examine the demand results (Table 3a). Notice that all own-price parameters are less than zero. All cross-price are greater than zero, although some are insignificant. Also note that the coefficient of the outside sales in category is positive, as expected. 
KADIYALI, CHINTAGUNTA, AND VILCASSIM

An Empirical Investigation of Pricing in a Local Market

Table 3a Demand and Cost Estimates from the Best-Fitting Game for Refrigerated Juice (Minimized sum of squared errors $=473.62$ )

\begin{tabular}{|c|c|c|c|c|}
\hline Parameter & Estimate & $\begin{array}{l}\text { Approx. } \\
\text { Std Err }\end{array}$ & $\begin{array}{c}\text { 'T' } \\
\text { Ratio }\end{array}$ & $\begin{array}{c}\text { Approx. } \\
\text { Prob > IT| }\end{array}$ \\
\hline \multicolumn{5}{|c|}{ MinuteMaid demand (brand 1) } \\
\hline Intercept & 2311764 & 1935482 & 1.19 & 0.2337 \\
\hline Own price & -5422983.4 & 399925.03 & -13.56 & 0.0001 \\
\hline Tropicana price & 2234034 & 914514.9 & 2.44 & 0.0154 \\
\hline Pvt label & 1040336 & 896636.9 & 1.16 & 0.2473 \\
\hline Outside category sales & 0.94 & 0.55 & 1.7 & \\
\hline Deal & 288.05 & 94.67 & 3.04 & 0.0027 \\
\hline \multicolumn{5}{|c|}{ Tropicana demand (brand 2) } \\
\hline Intercept & 7582326 & 1806028 & 4.2 & 0.0001 \\
\hline Minutemaid & 2268557 & 762758 & 2.97 & 0.0033 \\
\hline Own price & -8003637.1 & 429149.44 & -18.65 & 0.0001 \\
\hline Pvt label price & 1733501 & 851706 & 2.04 & 0.0431 \\
\hline Outside category sales & 0.95 & 0.57 & 1.65 & \\
\hline Deal & 146.56 & 94.61 & 1.55 & 0.1229 \\
\hline
\end{tabular}

Private label demand (brand 3)

\begin{tabular}{|c|c|c|c|c|}
\hline Intercept & 2539174 & 1838351 & 1.38 & 0.1687 \\
\hline Minutemaid price & 4012819 & 761182.3 & 5.27 & 0.0001 \\
\hline Tropicana price & 1108784 & 900860.1 & 1.23 & 0.2198 \\
\hline Own price & -7235777.2 & 435103.86 & -16.63 & 0.0001 \\
\hline Outside category sales & 0.10 & 0.07 & 1.5 & \\
\hline Deal & 96.61 & 85.72 & 1.13 & 0.2611 \\
\hline \multicolumn{5}{|l|}{ Marginal cost } \\
\hline Minutemaid & 1.79 & 0.05 & 34.08 & 0.0001 \\
\hline Tropicana & 2.02 & 0.04 & 46.67 & 0.0001 \\
\hline \multicolumn{5}{|l|}{ Conduct parameters } \\
\hline$\theta 1(r 1, m p 1)$ & 18.89 & 5.74 & 3.29 & 0.0012 \\
\hline$\theta 2(r 2, m p 1)$ & 20.09 & 7.59 & 2.65 & 0.0088 \\
\hline$\theta 3(ß 3, m p 1)$ & 13.31 & 22.53 & 0.59 & 0.5553 \\
\hline$\theta 4(r 1, m p 2)$ & 46.15 & 94.53 & 0.49 & 0.626 \\
\hline$\theta 5(r 2, m p 2)$ & -98.08 & 146.35 & -0.67 & 0.5035 \\
\hline$\theta 6(ß, m p 2)$ & -483.88 & 650.41 & -0.74 & 0.4578 \\
\hline$\theta 7(m p 1, r 1)$ & 14.68 & 7.28 & 2.02 & 0.0452 \\
\hline$\theta 8(m p 2, n)$ & 4.08 & 2.74 & 1.49 & 0.137 \\
\hline$\theta 9(m p 1,12)$ & -2.61 & 1.14 & -2.3 & 0.0226 \\
\hline$\theta 10(m p 2, r 2)$ & 0.95 & 0.52 & 1.83 & 0.068 \\
\hline$\theta 11(m p 1, ß 3)$ & -6.67 & 2.13 & -3.13 & 0.002 \\
\hline$\theta 12(m p 2, ß 3)$ & 0.01 & 1.10 & 0.01 & 0.9899 \\
\hline
\end{tabular}

The marginal cost estimates are all smaller than the average manufacturer prices, again as expected. MinuteMaid has lower costs than Tropicana, a ranking consistent with trade press evidence of Tropicana's
Table 3b Demand and Cost Estimates from the Best-Fitting Game for Tuna (minimized sums of squared errors $=682.14$ )

\begin{tabular}{|c|c|c|c|c|}
\hline Parameter & Estimate & $\begin{array}{l}\text { Approx. } \\
\text { Std Err }\end{array}$ & $\begin{array}{c}\text { 'T' } \\
\text { Ratio }\end{array}$ & $\begin{array}{c}\text { Approx. } \\
\text { Prob > ITI }\end{array}$ \\
\hline \multicolumn{5}{|c|}{ Chicken of the sea demand (brand 1) } \\
\hline Intercept & -1615587 & 461793.9 & -3.5 & 0.0006 \\
\hline Own price & -1194998.8 & 68481.306 & -17.45 & 0.0001 \\
\hline Starkist price & 787956.9 & 116490.2 & 6.76 & 0.0001 \\
\hline BumbleBee price & 18.20 & 93110.7 & 0 & 0.9998 \\
\hline Outside category sales & 226780.3 & 33806.4 & 6.71 & 0.0001 \\
\hline Deal & 21.73 & 19.61 & 1.11 & 0.269 \\
\hline \multicolumn{5}{|c|}{ Starkist demand (brand 2) } \\
\hline Intercept & 562191.6 & 242714.7 & 2.32 & 0.0215 \\
\hline COS price & 280489.5 & 69995.9 & 4.01 & 0.0001 \\
\hline Own price & -720683.33 & 32058.87 & -22.48 & 0.0001 \\
\hline BumbleBee price & 137436.2 & 57889.3 & 2.37 & 0.0185 \\
\hline Outside category sales & 39529.42 & 16884.4 & 2.34 & 0.0202 \\
\hline Deal & 16.54 & 9.75 & 1.7 & 0.0913 \\
\hline \multicolumn{5}{|c|}{ BumbleBee Demand (brand 3) } \\
\hline Intercept & 108330.2 & 181350.6 & 0.6 & 0.5509 \\
\hline COS price & 125525.2 & 54284.1 & 2.31 & 0.0218 \\
\hline Starkist price & 173542.7 & 53044.1 & 3.27 & 0.0013 \\
\hline Own price & -479618.16 & 22475.08 & -21.34 & 0.0001 \\
\hline Outside category sales & 44559.56 & 12941 & 3.44 & 0.0007 \\
\hline Deal & 5.71 & 6.10 & 0.94 & 0.3504 \\
\hline \multicolumn{5}{|l|}{ Marginal costs } \\
\hline $\cos$ & 7.72 & 0.41 & 18.8 & 0.0001 \\
\hline Starkist & 8.70 & 0.27 & 32.46 & 0.0001 \\
\hline BumbleBee & 8.15 & 0.83 & 9.88 & 0.0001 \\
\hline \multicolumn{5}{|l|}{ Conduct parameters } \\
\hline$\theta 1(r 1, m p 1)$ & -1.04 & $0.01-$ & -131.38 & 0.0001 \\
\hline$\theta 2(r 2, m p 1)$ & 0.01 & 0.014 & 0.69 & 0.4931 \\
\hline$\theta 3(ß 3, m p 1)$ & 156.30 & 799744.5 & 0 & 0.9998 \\
\hline$\theta 4(r 1, m p 2)$ & -0.65 & 0.69 & -0.93 & 0.3527 \\
\hline$\theta 5(r 2, m p 2$ & -3.12 & 0.37 & -8.3 & 0.0001 \\
\hline$\theta 6(ß 3, m p 2)$ & -0.40 & 2.71 & -0.15 & 0.8814 \\
\hline$\theta 7(r 1, m p 3)$ & 0.01 & 0.009 & 1.1 & 0.2733 \\
\hline$\theta 8(r 2, m p 3)$ & 0.021 & 0.011 & 2.2 & 0.029 \\
\hline$\theta 9(ß 3, m p 3)$ & -1.06 & 0.008 & -126.78 & 0.0001 \\
\hline$\theta 10(m p 1, n)$ & -1.03 & 0.007 & -150.95 & 0.0001 \\
\hline$\theta 11(m p 2, n)$ & 0.008 & 0.012 & 0.65 & 0.5196 \\
\hline$\theta 12(m p 3, n)$ & -0.03 & 0.017 & -1.84 & 0.0666 \\
\hline$\theta 13(m p 1$, ґ2) & -0.24 & 0.14 & -1.64 & 0.1026 \\
\hline$\theta 14(m p 2$, ґ2) & -2.60 & 0.16 & -16 & 0.0001 \\
\hline$\theta 15(m p 3$, r2) & 0.625921 & 0.33 & 1.88 & 0.0617 \\
\hline$\theta 16(m p 1, ß)$ & 0.01 & 0.007 & 1.47 & 0.1431 \\
\hline$\theta 17(m p 2$, ß) & 0.018 & 0.01 & 1.63 & 0.105 \\
\hline$\theta 18(m p 3$, ß) & -1.06 & $0.008-$ & -129.72 & 0.0001 \\
\hline
\end{tabular}


"not from concentrate" positioning and superior packing being more expensive than MinuteMaid's (e.g., Business Week 1996).

As Table 4a indicates, the retailer gets a larger share of channel profits in this market. Specifically, the retailer gets about $66.03 \%$ of the channels profit on MinuteMaid and about $58.63 \%$ of Tropicana. According to our definition, this means that the retailer has greater pricing power in this channel.

Looking at the game that the retailer plays with these manufacturers, we see that $\theta_{1}\left(r_{1}, m p_{1}\right)$ which represents how the retailer interacts with the manufacturer of Minute Maid in setting the retail markup for Minute Maid is positive (18.89) and significant. But $\theta_{5}\left(r_{2}, m p_{2}\right)$ which represents how the retailer interacts with the manufacturer of Tropicana in setting the retail markup for Tropicana is not significantly different from zero. This means the retailer is pricing more competitive than Nash with MinuteMaid but is pricing Nash with Tropicana. In manufacturer games, our calculations show that manufacturers are both pricing more competitively than Nash, with Tropicana being less competitive than MinuteMaid. Therefore, we see that the MinuteMaid-retailer pair is more fiercely competitive than Tropicana-retailer pair.

What factors explain these games and retailer pricing power? It is tempting to conjecture that retailer's pricing power comes from its large market share. It could also be the case that retailer power results from intense competition between MinuteMaid and Tropicana (see Business Week, 1996). Given that we do not have a way to estimate intermanufacturer competition, we cannot verify if this conjecture is true. Clues for the game patterns and retailer pricing power are to be found in the underlying demand and cost conditions.

Table 5a shows the estimated demand elasticities. Consistent with accepted wisdom, the private label has the highest own-price elasticity. It also has the lowest absolute price, and the cost of the private label (or its wholesale price) is lower than that of the two national brands. There are also some interesting demand hierarchies-while MinuteMaid demand is not affected by private label price (parameter not significant), the private label demand has a significant cross-price elasticity with respect to MinuteMaid. Also, while Tropicana demand is affected by private label price, the reverse
Table 4a Profit and Market Shares for Refrigerated Juice

\begin{tabular}{lccc}
\hline & MinuteMaid & Tropicana & Private label \\
\hline Retail price $(p)$ & 2.78 & 3.35 & 2.06 \\
Manufacturer price $(m p)$ & 2.02 & 2.46 & 1.43 \\
Retailer mark-up $(p-m p)$ & 0.76 & 0.89 & 0.61 \\
Retailer channel profit share & $66.03 \%$ * & $58.67 \%$ * & not estimated \\
Estimated marginal cost $(m c)$ & 1.79 & 2.02 & not estimated \\
Manufacturer mark-up $(m p-m c)$ & 0.23 & 0.46 & not estimated \\
Manufacturer channel profit share* & $33.97 \%$ * & $41.33 \%{ }^{*}$ & not estimated \\
Market share & $29.64 \%$ & $39.86 \%$ & $30.51 \%$ \\
\hline
\end{tabular}

*Calculated per Equation (12), the other numbers are simple averages over the entire time period)

Table 4b Profit and Market Shares for Tuna

\begin{tabular}{lccc}
\hline & COS & StarKist & BumbleBee \\
\hline Retail price $(p)$ & 12.15 & 13.96 & 14.65 \\
Manufacturer price $(m p)$ & 9.49 & 10.7 & 10.84 \\
Retailer mark-up $(p-m p)$ & 2.66 & 3.26 & 3.81 \\
Retailer channel profit share* & $71.75 \%$ * & $60.59 \%$ * & $56.59 \%$ * \\
Estimated marginal cost $(m c)$ & 7.72 & 8.70 & 8.15 \\
Manufacturer mark-up $(m p-m c)$ & 1.78 & 2.1 & 2.69 \\
Manufacturer channel profit share* & $28.25 \%$ * & $39.41 \%$ * & $43.41 \%$ * \\
Market share & $35.27 \%$ & $39.88 \%$ & $24.84 \%$ \\
\hline
\end{tabular}

Calculated per Equation (12), the other numbers are simple averages over the entire time period)

Tables 5a and 5b Demand Elasticities for Refrigerated Juice and Tuna

\begin{tabular}{lccc}
$\begin{array}{l}\text { Demand Elasticity of Brand } \\
\text { Below with Respect to } \rightarrow\end{array}$ & MinuteMaid & Tropicana & Pvt label \\
\hline MinuteMaid & -2.16 & 0.9 & n.s. \\
Tropicana & 0.64 & -2.26 & 0.5 \\
Private label & 1.46 & n.s. & -2.64 \\
\hline Demand Elasticity of Brand & & & \\
Below with Respect to $\rightarrow$ & COS & Starkist & BumbleBee \\
\hline COS & & & \\
Starkist & -5.9 & 3.89 & n.s. \\
BumbleBee & 1.25 & -3.2 & 0.61 \\
\hline
\end{tabular}


is not true. Given that MinuteMaid is not affected by private label pricing, it can price more competitively than Tropicana. MinuteMaid also has lower cost structure than Tropicana, which is consistent with more aggressive pricing, too.

Summarizing, we find that the cross-price demand elasticities are consistent with the retailer's differential behavior toward the two brands. The retailer is more competitive with the brand that can affect its private label demand, and the brand that prices more aggressively with the retailer (Minute Maid). The larger intercept or larger latent loyalty, as well as larger market share of Tropicana (relative to MinuteMaid) translate to a larger share of channel profits $(41.13 \%)$ relative to MinuteMaid (about 34\%).

4.2.2. Channel Interactions in Tuna. Table $3 b$ shows that in the case of the tuna category also, the own-price elasticities are negative and the cross-price elasticities are positive, as expected. The outside sales in category variable is positive and significant, also as expected. Additionally, the estimated marginal costs are all significant, positive, and have lower values than the respective average manufacturer prices. Starkist has the highest cost, consistent with trade press discussions of Heinz's high-cost structure (see Forbes 1998). We could not find supporting evidence for whether Chicken of the Sea is indeed the lowest cost, partly because both COS and Bumble Bee were foreign-owned during the time period studied (COS was owned by an Indonesian company and Bumble Bee by Thai-based Unicord).

Table $4 \mathrm{~b}$ shows that the retailer has pricing power in this category as well. The retailer makes $71.75 \%$ of Chicken of the Sea, $60.59 \%$ of StarKist, and $56.59 \%$ of BumbleBee channel profits. This is an interesting finding, given that the retailer does not have a significant private label offering in this category, unlike in refrigerated juice. Because we cannot disentangle intermanufacturer power, we cannot tell if retailer power is coming from fierce competition between manufacturers (see Forbes 1998 for anecdotal evidence that this competition is intense).

Looking at the game that the retailer plays with these manufacturers, Table $3 \mathrm{~b}$ shows that all three retailer conduct parameters with respect to manufacturer pricing are negative and significant. Specifically, $\theta_{1}\left(r_{1}, m p_{1}\right)$ is $-1.04, \theta_{5}\left(r_{2}, m p_{2}\right)$ is -3.11 , and $\theta_{9}\left(r_{3}, m p_{3}\right)$ is -1.06 . Therefore, the retailer is pricing competitively with all three manufacturers. The impact of this is largest on COS profits, next on Starkist, and the least impact on profits for BumbleBee. In other words, competitive pricing is fiercest with COS, more than Starkist, which in turn is more than with BumbleBee (the order of retailer's share of channel profits is related directly to how fiercely it competes). Table $5 \mathrm{~b}$ shows demand elasticities for these three brands. We see that COS seems weakest of all three brands on the demand side. It has the highest own-price elasticities and the worst intercept (negative and significant) in the demand function. Both of these point to poor loyalty or brand preference and high vulnerability to other brands. These facts are consistent with the retailer's pricing being most aggressive with respect to COS.

In manufacturer games, we find all manufacturers price more competitively than Nash. In order of competitiveness, COS prices more competitively than BumbleBee, which in turn prices more competitively than Starkist. The estimated cost of COS is the lowest of the three brands, which is consistent with COS pricing most aggressively.

In summary, this market has all-round competitive pricing. The retailer's most competitive stance is with respect to COS, the brand with the most demand disadvantages. On the manufacturer side, COS prices most aggressively, consistent with its lowest cost position. The retailer has overall power in this market, even though it does not have a significant private label program.

4.2.3. Comparing Refrigerated Juice and Tuna. From the previous two subsections, we find that the retailer has pricing power in both categories. Given that there is no private label in tuna, this analysis provides evidence that private labels are not necessary for the retailer to have pricing power. Curiously, we also find that the retailer has more average pricing power (larger share of channel profits) in the category without private labels, i.e., in tuna.

We also find that the retailer is pricing less competitively in the product category where it has a private label offering (Nash pricing with Tropicana compared to competitive pricing to all brands in the tuna category). This makes sense in that the retailer has more at 
stake directly in this market. Therefore, across both products, we find that the games being played in this marketing channel are consistent with underlying demand and cost parameters.

The results above are subject to the caveat that we discussed in \$3.1, where we discussed what components of manufacturer cost, and especially what components of retailer cost we might not be capturing in our model. Specifically, any variable cost to the retailer not captured by our manufacturer price series will overstate the retailer's share of channel profits. Also, we have not accounted for fixed costs of either manufacturers or retailers. These affect not the channel variable profit division, but rather the channel members' bottom line total profits.

Subject to this caveat, how can we reconcile our results of retailer having more power when retailer rate of returns have been computed to be low in COMPUSTAT and other databases (Messinger and Narasimhan 1995)? As we have mentioned, retailers could be capturing channel profits if manufacturer competition is intense, as the trade press says is the case in these two categories. We have also mentioned that the model does not account for fixed costs, and these could also lead to the observed low rates of return seen by previous studies, which use standard accounting profit measures. More studies are needed to confirm these hypotheses.

\section{Conclusion}

We have estimated a structural model of manufacturer-retailer interactions to determine where pricing or market power lies in this interaction. We built a general model of channel interactions to estimate which party in the manufacturer-retailer interaction has how much market pricing power and why. We provide a tractable analytic model to accomplish this task. Additionally, we test if some of the channel interaction models proposed in the extant literature are consistent with market data.

Our empirical results for the refrigerated juice product category for a major retail chain in the Midwest indicates that the retailer has substantial pricing power. This is true even in the tuna category, where there is no significant private label. Therefore, manufacturer pricing power, as measured by manufacturer markup, is less than retailer pricing power for each of the national brands. The results are consistent with trade press evidence of intense manufacturer competition in these categories and with the "commodity" image of these two categories. We also find that the vertical Nash, manufacturer Stackelberg leader, and retailer Stackelberg leader models are rejected in favor of our proposed specification. Future research in the theoretical marketing channels literature should therefore consider alternative channel interaction models to more comprehensively represent market behavior.

There are several possible directions for future empirical research. One such course is to use individuallevel data to better determine brand-switching patterns between national and private label products. Another extension is using more general demand and cost specifications. In the current setup, we have restricted ourselves to single-log demand and constant marginal cost for analytical tractability. To have a general demand specification, the logit demand framework is very appealing because it can accommodate parsimoniously a large number of brands within a product category. Additionally, this model has been found to empirically perform well as a representation of demand in a variety of market situations. An analysis using the logit model would be an extension of the Karunakaran (1998) and Besanko et al. (1999) model of channel interaction. We note that the latter paper examines Nash pricing with category profit maximization by retailer, a situation in which logit demand framework produces the unappealing result of equal absolute markups across all brands. Therefore, if the logit demand model were to be used to examine channel interactions, then it is imperative to consider a richer set of channel interaction regimes than the Nash case to get more realistic profit margin implications.

Another useful extension would be to include retaillevel competition in the analysis and use the LeeStaelin framework, along with our generalizations to model channel behavior. Also interesting would be to examine the issue of manufacturers pricing product lines in channels. Both of those would be more realistic models than the present one but raise serious estimation issues. Nevertheless, data permitting, those are issues that merit investigation.

Finally, we note that the analysis of power in the 
retailer-manufacturer interaction in this study is limited to price-setting behavior. There are several other strategic decision variables in a channel relationship, such as slotting fees and advertising, which also determine power. Hence, a broader analysis of channel power and interaction would be insightful. Additionally, it would also be interesting to study how power has shifted over time, perhaps by making the conduct parameter a time-varying function (of covariates of competition) or by splitting the data set in two time periods and test if conduct parameters have changed over time. Hence, there is both an opportunity and a need for further empirical research in this area.

In extending the NEIO approach in the directions suggested above, we would like to include some words of caution. There are at least three ways in which the methodology is sensitive to data. First, the estimation efficiency is dependent on good instrumental variables, on both the demand and the cost side. In our study, we have the outside sales in the category as an exogenous variable and hence a demand-side instrument. However, we could not find good material costs (e.g., raw orange prices or raw tuna prices) on a weekly basis. Future studies need to address this issue better. Second, the estimation is sensitive to misspecification in any equation, which can spread to all equations because of the system-of-equations estimation. However, given that cross-equation parameter restrictions are critical in such models, the system of equations approach is essential. In our study, we have performed specification tests where possible to ensure that our assumptions/formulations were consistent with the data. Additionally, future studies should explore alternative estimation methodologies (e.g., GMM) that have more general error structure assumptions. The third way in which the results are sensitive to the data is the cross-equation restrictions make the impact of any one incorrect data series spread through the entire system as well (i.e., in addition to misspecification). Examples include incorrect aggregating across different qualities of private brand and trying to fit the model across not-strictly-comparable product categories (e.g., should Gatorade be included with nonrefrigerated juices?). Therefore, these three dimensions of sensitivity of the NEIO approach should be kept in mind in future applications.
In summary, this study is one of the first to examine the empirically validity of some of the channel pricesetting arrangements that have been proposed in the theoretical marketing literature. Despite the heavy demands that such models place on the data, we have been able to obtain results that seem prima facie reasonable and provide insights into channel pricing power. Our results also show that the nature of the channel price setting arrangements seems to be much richer than those that have been examined in the theoretical channels literature. Future studies can shed more light into this important marketing issue by including more factors that determine channel power. ${ }^{11}$

\section{References}

Besanko, D., S. Gupta, D. Jain. 1999. Logit demand estimation under competitive pricing behavior: An equilibrium framework. Management Sci. 38 1732-1749.

Bresnahan, T. F. 1989. Industries and market power. Handbook of Industrial Organization. R. Schmalensee and R. Willig (eds.), North Holland, Amsterdam.

Borin, N., P. Farris. 1990. An empirical comparison of direct product profit and existing measures of SKU productivity. J. Retailing 66(3) 297-314.

Choi, S. 1991. Price competition in a channel structure with a common retailer. Marketing Sci. 10(4) 271-296.

Connor, J., E. Peterson. 1992. Market structure determinants of national brand-private label price difference of manufactured food products. J. Indust. Econom. 40 157-171.

Cotterill, R., R. Dhar, B. Putsis. 1997. Market share and price-setting behavior for private label and branded food products: An empirical analysis. Working paper, Yale School of Management, New Haven, CT.

Coughlan, A. 1985. Competition and cooperation in marketing channel choice: Theory and application. Marketing Sci. 4 110-129.

— B. Wernerfelt. 1989. On credible delegation by oligopolists: A discussion of distribution channel management. Management Sci. 35 226-239.

Farris, P., K. Ailawadi. 1992. Retailer power: Monster or mouse? J. Retailing 68(4) 351-369.

\footnotetext{
${ }^{11}$ The authors would especially like to thank the Area Editor and the Editor, as well as the two reviewers for several comments and suggestions that have vastly improved the paper, and Peter Rossi for the use of the Dominick's data. They are also grateful to P.B. Seetharaman for excellent research assistance. They thank Andrew Ainslie, Eric Anderson, Glen Ellison, Sudhir Karunakaran, Matt Shum, Vithala Rao, and Dick Wittink; participants at Marketing Science 1997, Berkeley, and Marketing Workshop participants at Dartmouth College, Pittsburgh, UC-Berkeley, and Wharton; and NBER Summer I.O. Conference participants for their comments and suggestions.
} 
Gelfand, M., P. Spiller. 1987. Entry barriers and multiproduct firms: Do they forebear or spoil? Internat. J. Indust. Organ. 5 101-113.

Greene, W. 1990. Econometric Analysis, MacMillan Publishing Company, NY.

Hausman, J. 1978. Specification tests in econometrics. Econometrica 46 1251-1272.

Hoch, S. 1996. How should national brands think about private labels? Sloan Management Rev., 37(2) 89-102.

—, S. Banerjee. 1993. When do private labels succeed? Sloan Management Rev. 34(4) 57-67.

Jeuland, A., S. Shugan. 1988. Channels of distribution profits when channel members form conjectures. Marketing Sci. 2 161-190.

Johnson, W. C. 1988. Sales promotions: It comes down to push marketing. Marketing News February 8.

Jones, J. P. 1990. The double jeopardy of sales promotions. Harvard Bus. Rev. September-October 145-152.

Karunakaran, S. 1998. Structural analysis of manufacturer pricing in the presence of a strategic retailer. Working paper, Stern School, New York University, NY.

Krishnan, T., H. Soni. 1997. Guaranteed profit margins: A demonstration of retailer power. Internat. J. Res. Marketing 14(1) 35-56.

Lee, Eunkyu, R. Staelin. 1997. Vertical strategic interaction: Implications for channel pricing strategy. Marketing Sci. 16(3) 185207.

McGuire, T., R. Staelin. 1983. An industry equilibrium analysis of downstream vertical integration. Marketing Sci. 2 161-190.

Messinger, P., C. Narasimhan. 1995. Has power shifted in the grocery channel? Marketing Sci. 14(2) 189-223.
Narasimhan C., R. Wilcox. 1996. Private labels and the channel relationship: A cross-category analysis. Working paper, Olin School of Business, Washington University, St. Louis, MO.

Parker, P., N. Kim. 1996. National versus private label brands: An empirical study of competition, advertising and collusion. Working paper, INSEAD, Fontainebleau, France.

L. Roller. 1997. Collusive conduct in duopolies: Multimarket contact and cross-ownership in the mobile telephone industry. Rand J. Econom.

Raju, J., S. Dhar, R. Sethuraman. 1995. The introduction and performance of store brands. Management Sci. 41(6) 957-978.

Roberts, M., L. Samuelson. 1988. An empirical analysis of dynamic, nonprice competition in an oligopolistic industry. Rand $J$. Econom. 19(2) 200-220.

Salmon, W., K. Cmar. 1987. Private labels are back in fashion. Harvard Bus. Rev. 63(3) 99-106.

Slade, M. 1995. Product rivalry with multiple strategic weapons: An analysis of price and advertising competition. J. Econom. Management Strategy 4(3) 445-476.

Spencer, D., K. Berk. 1981. A limited information specification test. Econometrica 49 1079-1085.

Spiller, P., E. Favaro. 1984. The effects of entry regulation on oligopolistic interaction: The Uruguan banking sector. Rand J. Econom. 15(4) 244-254.

Stern, L., A. El-Ansary, A. Coughlan. 1996. Marketing Channels. 5th Edition, Prentice Hall, Upper Saddle River, NJ.

Vuong, Q. H. 1989. Likelihood ratio tests for model selection and non-nested hypotheses. Econometrica 57(2) 307-333.

This paper was received September 18, 1998, and was with the authors 6 months for 3 revisions, processed by William Boulding. 